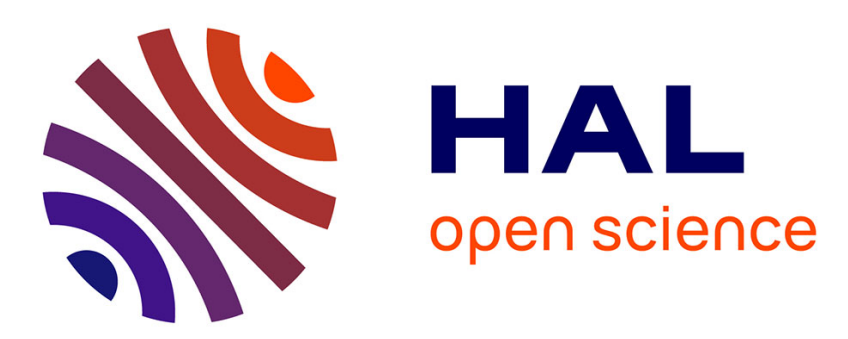

\title{
ENERGY BASED STRUCTURAL MODELLING - A PRACTICAL APPROACH FOR COMPLEX STRUCTURES
}

\author{
G. Stimpson, N. Lalor, G. Borello
}

\section{- To cite this version:}

G. Stimpson, N. Lalor, G. Borello. ENERGY BASED STRUCTURAL MODELLING - A PRACTICAL APPROACH FOR COMPLEX STRUCTURES. Journal de Physique IV Proceedings, 1992, 02 (C1), pp.C1-475-C1-478. 10.1051/jp4:19921102 . jpa-00251056

\section{HAL Id: jpa-00251056 https://hal.science/jpa-00251056}

Submitted on 1 Jan 1992

HAL is a multi-disciplinary open access archive for the deposit and dissemination of scientific research documents, whether they are published or not. The documents may come from teaching and research institutions in France or abroad, or from public or private research centers.
L'archive ouverte pluridisciplinaire HAL, est destinée au dépôt et à la diffusion de documents scientifiques de niveau recherche, publiés ou non, émanant des établissements d'enseignement et de recherche français ou étrangers, des laboratoires publics ou privés. 


\title{
ENERGY BASED STRUCTURAL MODELLING - A PRACTICAL APPROACH FOR COMPLEX STRUCTURES
}

\author{
G. STIMPSON, N. LALOR and G. BORELLO* \\ Institute of Sound and Vibration Research, The University of Southampton, GB-Southampton \\ SO9 5NH, Great-Britain \\ *Ingénieur Conseil, 1 Impasse des Hinoudelles, F-31240 L'Union, France
}

\begin{abstract}
Recent improvements in the calculation of coupling factors from direct measurements have made Energy Based Structural Modelling more practical. Application to an aerospace structure is described.
\end{abstract}

\section{INTRODUCTION}

Energy analysis methods provide a technique for noise and vibrational modelling of interconnected or built up structures. The technique is particularly applicable in the high frequency ranges where structural wavelengths are short and vibrational characteristics localised. The use of these techniques in a purely theoretical manner i.e. Statistical Energy Analysis (SEA) has been limited, however, to all but very simply shaped structures because of the difficulties of accurately predicting the coupling factors and modal densities involved. An alternative method is to incorporate measured data taken from an actual structure or prototype. This forms more of an experimental design model which, although lacking some of the absolute predictive capabilities of one based solely on theoretical calculations, still provides a very powerful tool for development and diagnostics.

Uses include the determination of important energy transmission paths, predictions of noise radiation, sensitivity analysis and the prediction and optimisation of the effects of noise control treatments. The term Energy Flow Analysis (EFA) is used to designate this form of analysis procedure. 
Some practical difficulties still exist, however, mainly:

1. Uncertainty in determining subsystem modal densities;

2. Difficulty in calculating true subsystem energies from vibration measurements.

The first problem can be overcome by use of the consistency relationships that exist between two coupled subsystems $i$ and $j:$

$$
\begin{array}{ll}
n_{i} \eta_{i j}=n_{j} \eta_{j i} & \text { where } n_{i}, n_{j} \text { are modal densities, } \\
& \eta_{i j}, \eta_{j i} \text { are coupling loss factors. }
\end{array}
$$

Reference 2 shows how these relationships can be used, together with the power injection technique (3), to obtain both the internal and the coupling loss factors of a complex structure without a knowledge of modal densities and without having to physically disconnect the individual subsystems. The second problem can be partly solved by introducing the concept of Equivalent Mass. This is the mass which, when multiplied by the spatial and time averaged square of the subsystem velocity, gives the total subsystem energy. It is assumed here that, for a complex three dimensional structure, all the wave types couple together. Reference 3 gives details of how this equivalent mass can be measured.

\section{IMPROVEMENTS TO METHOD OF LOSS FACTOR DETERMINATION}

I. Internal Loss Factor The internal loss factors can be calculated independently. This is done by considering the power balance of the total system when power is input into each subsystem in turn, i.e. the input power to any one subsystem must be equal to the total power dissipated in all the subsystems, viz:

$$
\begin{aligned}
& \overline{\mathrm{P}}_{1}=\omega\left(\overline{\mathrm{E}}_{11} \eta_{1}+\overline{\mathrm{E}}_{21} \eta_{2}+\ldots \ldots . .+\overline{\mathrm{E}}_{\mathrm{N} 1} \eta_{N}\right) \\
& \vdots \\
& \overline{\mathrm{P}}_{\mathrm{N}}=\omega\left(\overline{\mathrm{E}}_{1 \mathrm{~N}} \eta_{1}+\overline{\mathrm{E}}_{2 \mathrm{~N}} \eta_{2}+\ldots \ldots .+\overline{\mathrm{E}}_{\mathrm{NN}} \eta_{\mathrm{N}}\right)
\end{aligned}
$$

which on rearranging and writing in matrix form gives:

$$
\left[\begin{array}{c}
\eta_{1} \\
\vdots \\
\eta_{\mathrm{N}}
\end{array}\right]=\frac{1}{\omega}\left[\begin{array}{ccc}
\mathrm{E}_{11} & \ldots \ldots . . & \mathrm{E}_{\mathrm{N} 1} \\
\vdots & & \vdots \\
\mathrm{E}_{1 \mathrm{~N}} & \ldots \ldots . . & \mathrm{E}_{\mathrm{NN}}
\end{array}\right]-1\left[\begin{array}{c}
\tilde{P}_{1} \\
\vdots \\
\tilde{\mathrm{P}}_{\mathrm{N}}
\end{array}\right]
$$

It should be noted that the internal loss factors are calculated from equation [2] without having to make any assumptions about the way that energy flows between subsystems. The energy matrix is also well conditioned (the large $\overrightarrow{\mathrm{E}}_{\mathrm{i} i}$ terms only occur on the leading diagonal).

II. Coupling Loss Factors Use is made of the fact that some of the coupling loss factors are known i.e. those which relate to unconnected subsystems are zero. The power balance equations can therefore be grouped together and partitioned so that all the terms relating to connected subsystems are contained in one section of the matrix i.e. 


$$
\omega\left[\begin{array}{ll}
E_{\alpha \alpha} & E_{\alpha \beta} \\
E_{\beta \alpha} & E_{\beta \beta}
\end{array}\right]\left[\begin{array}{l}
\eta_{\alpha} \\
\eta_{\beta}
\end{array}\right]=\left[\begin{array}{l}
P_{\alpha} \\
P_{\beta}
\end{array}\right], \quad \begin{aligned}
& \text { where } \alpha \text { denotes a connection } \\
& \text { and } \beta \text { no connection. }
\end{aligned}
$$

As the $\eta_{\beta}$ matrix is composed of zero's a reduced calculation can be performed only using the $\mathrm{E}_{\alpha \alpha}$ matrix. In fact for the relatively weak coupling of many practical structures the $E_{\alpha \alpha}$ matrix is dominated by its diagonal terms and very little error and much simplification is introduced by neglecting the off diagonals. This leads to a direct relationship for the individual coupling loss factors without the need for any matrix inversion i.e:

$$
\eta_{i j} \simeq \frac{1}{\omega}\left(\frac{E_{i j}}{E_{i i}}\right)\left(\frac{P_{j}}{E_{j j}}\right)
$$

A very important aspect of equation [4] is that it enables the coupling loss factors between two coupled subsystems to be calculated from measurements made only on those two subsystems, regardless of how many other subsystems exist.

III. Consistency Relationships For more than 3 subsystems there is extra information available from the power injection tests that has hitherto been unused. This can be utilised via the relationship, (ref 4).

i.e. $\eta_{i j} \eta_{j k} \eta_{k i}=\eta_{j i} \eta_{i k} \eta_{k i}$ and hence $P_{i j} P_{j k} P_{k i}=P_{j i} P_{i k} P_{k i}$

where $P_{1 m}=$ power flowing from subsystem 1 to subsystem $\mathrm{m}$.

Thus, the product of the powers flowing in each branch of the loop clockwise is equal to the product flowing anti-clockwise. This suggests an analogy with electrical circuit theory and is worthy of further investigation.

\section{APPLICATION}

Recently, applications of these techniques have been made in both automotive and aerospace industries. A 40 sub system model of a car body structure has been developed and used to optimise the placement of noise control treatments. Also, current work is being undertaken to model the high frequency vibrational response of the Vulcan engine used in the Arianne rocket shown in Figures 1 and 2. A simple 8 sub system model has been created initially (Figure 3) and coupling loss factors measured using an impact excitation method. Some typical damping loss factors (DLF) and coupling loss factors (CLF) are shown in Figures 4 and 5. The object of the study is to predict the response of the engine structure during the launch phase of the rocket when excitation is both from the engine itself and the very intense surrounding acoustic field due to the firing of the two solid fuel booster rockets.

\section{REFERENCES}

1. R H Lyon. Statistical Energy Analysis of Dynamical Systems: Theory and Application M.I.T Press (1973).

2. N Lalor. The Measurement of SEA Loss on a Fully Assembled Structure. ISVR Technical Report No. 150, August 1987.

3. N Lalor. The experimental Determination of Vibrational Energy Balance in Complex Structures. Paper No. 1084 29, SIRA conference "Stress and Vibration: Recent Developments in Industrial measurement and Analysis". London March 1989.

4. N Lalor. Practical Considerations for The Measurement of Internal and Coupling Loss Factors on Complex Structures. ISVR Technical Report No 182 June 1990. 


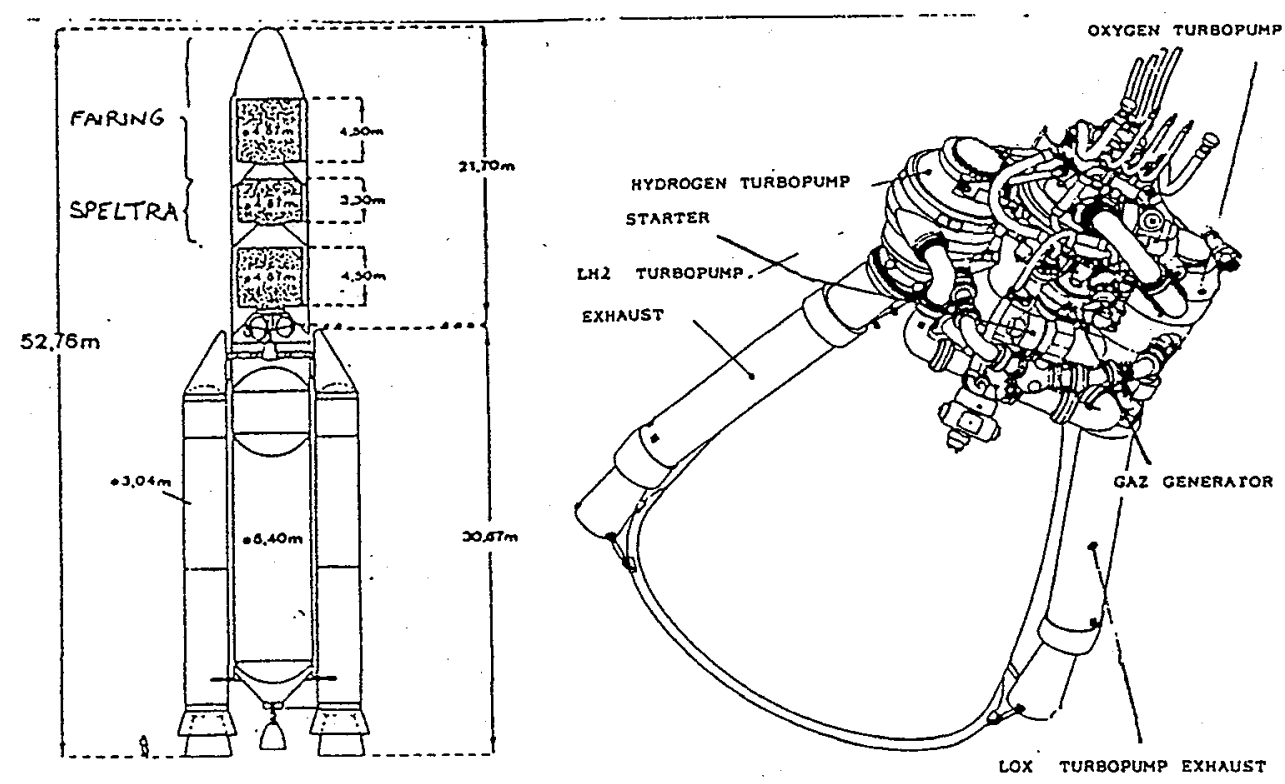

Fig.1 Sketch of the Ariane 5 configuration Fig.2 The VULCAIN engine

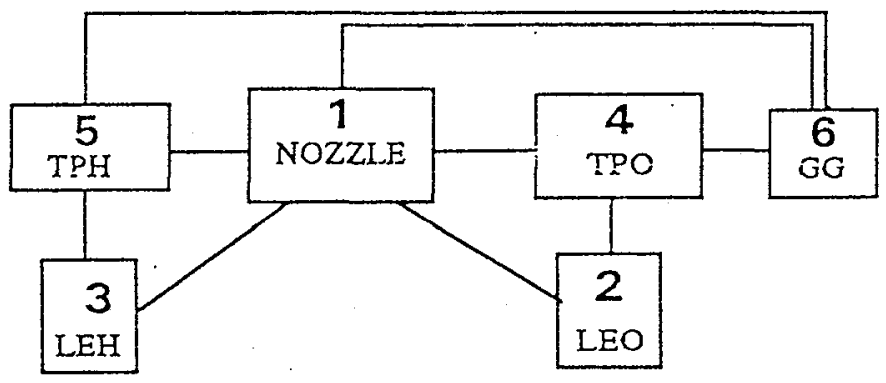

Fig.3 Energy flow model for the VULCAIN engine

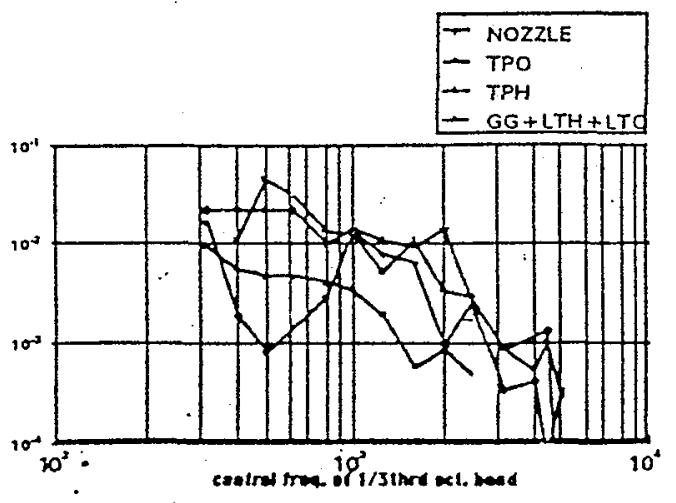

Fig.4 :DLF of the main components of the engine

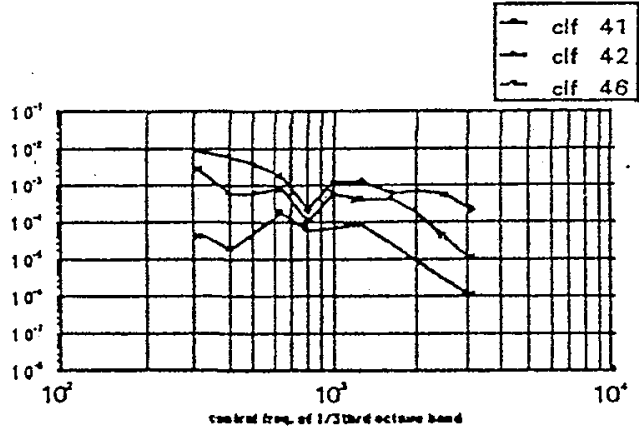

Fig5 : CLF between the TPO2 and the connected componants ref. fig 3 